\title{
SOBRE A PROPOSIÇÃo DE QUE TODo NúMERo PERFEITo É UM NúMERo Triangular
}

\author{
John A. Fossa \\ Universidade Estadual da Paraíba - UEPB - Brasil
}

(aceito para publicação em novembro de 2020)

\begin{abstract}
Resumo
A proposição de que todo número perfeito é um número triangular era conhecida desde a antiguidade, pois foi conhecida por Jâmblico e, provavelmente, Nicômaco. Depois de considerar os quatro tipos de perfeição dados por Jâmblico, apresenta-se as demonstrações de Jordanus, Bouvelles (demonstração por exemplificação) e Maurolico para a referida proposição. Todas elas supõem, no entanto, a recíproca do teorema IX.36 de Euclides, que só foi demonstrada, para números perfeitos pares, posteriormente por Euler.
\end{abstract}

Palavras-chave: Números Perfeitos, Números Triangulares, Números Hexagonais, Demonstração por exemplificação.

\section{[ON THE PROpOSition THAT \\ Every Perfect Number is a Triangular Number]}

\begin{abstract}
The proposition that every perfect number is a triangular number was known from Antiquity, since it was known by Iamblichus and, probably, by Nicomachus. After considering the four types of perfection given by Iamblichus, we present demonstrations by Jordanus, Bouvelles (proof by exemplification) and Maurolico for the stated proposition. All of them, however, share the same defect in that they presume the reciprocal of Euclid IX.36, which was only demonstrated, for even perfect numbers, later by Euler.
\end{abstract}

Keywords: Perfect Numbers, Triangular Numbers, Hexagonal Numbers, Proof by Exemplification. 


\section{Introdução: Os Fundamentos}

Um número perfeito é um número (inteiro positivo) que é igual à soma das suas partes alíquotas, onde por parte alíquota se entende divisor positivo menor do que o referido número. O menor número perfeito é 6 . As partes alíquotas de 6 são 1,2 e 3 e, de fato, $6=$ $1+2+3$. O conceito de número perfeito provavelmente remonta à antiguidade remota, mas 0 primeiro tratamento matemático dele que temos é o de Euclides (fl. c. 300 a.C.). Na definição $23^{1}$ do Livro VII de Os Elementos, lemos:

"Um número perfeito é o que é igual às suas próprias partes." (EUCLIDES, 2009, p. 270.)

A proposição 36 do Livro IX de Os Elementos afirma:

"Caso números, quantos quer que sejam, a partir da unidade, sejam expostos, continuadamente, na proporção duplicada, até que o que foi composto todo junto se torne primo, e o todo junto, tendo sido multiplicado pelo último, faça algum, o produzido será perfeito." (EUCLIDES, 2009, p. 349.)

Isto é, começamos com a sequência de $k$ termos, $1,2,4, \ldots, 2^{k-1}$, em que $1+2+4+\ldots+2^{k-1}$ é um número primo. Então,

$$
2^{k-1}\left(1+2+4+\ldots+2^{k-1}\right)
$$

será um número perfeito. A série geométrica contida nessa expressão pode ser avaliada usando proposição IX.35 de Os Elementos, nos fornecendo a seguinte expressão para números perfeitos:

$$
2^{k-1}\left(2^{k}-1\right)
$$

Visto que será importante no que segue, observamos explicitamente que a proposição IX.36 afirma o seguinte:

$$
p=2^{k-1}\left(2^{k}-1\right) \Rightarrow p \text { é perfeito. }
$$

A recíproca, limitada aos números perfeitos pares, foi dado por Euler (1849) ${ }^{2}$. A existência de números perfeitos ímpares ainda está em aberto.

Também conhecidos desde a antiguidade são os números figurados. Esses correspondem, intuitivamente, às quantidades de unidades (geralmente representadas por

\footnotetext{
${ }^{1}$ Na tradução de Heath, isto é Definição 22. Ver Euclid (1956).

${ }^{2} \mathrm{O}$ artigo referenciado é um de três artigos com o mesmo título escritos por Euler. Trata-se de E798, publicado postumamente. A referida demonstração se encontra em §8. Os três artigos são reunidos e traduzidos em Euler (2015).
}

RBHM, Vol. 20, n 40, pp. 32-45, 2020 
pequenos círculos ou "pontos”3) usadas para formar figuras geométricas. Em especial, os números triangulares são as quantidades que formam triângulos equiláteros. Desta forma, para $n>1$, o $n$-1-ésimo número triangular é um triângulo de lado $n-1$ e seu valor é dado pela soma $1+2+3+\ldots+n-1$, o que pode ser calculado 4 pela expressão $\frac{n(n-1)}{2}$.

Dado tudo isso, é um exercício trivial mostrar que, notavelmente, todo número perfeito par é triangular, pois $2^{k-1}=\frac{2^{k}}{2}$ e, portanto, $2^{k-1}(k-1)=\frac{2^{k}\left(2^{k}-1\right)}{2}$, o que tem a forma geral $\frac{n(n-1)}{2}$ dos números triangulares. Na ausência do simbolismo algébrico moderno, porém, o reconhecimento desse fato e, ainda mais, a sua demonstração, é decididamente mais desafiante. Nicômaco de Gerasa, por exemplo, na sua Introdução à Aritmética, dá os seguintes números perfeitos: 6, 28, 496 e 8128 (I.16). Ele também dá os primeiros dez números triangulares: $1,3,6,10,15,21,28,36,45$ e 55 (II.12). Visto que 6 e 28 são comuns às duas listas, ele poderia ter especulado que os números perfeitos são todos ${ }^{5}$ triangulares. No entanto, não fez isso.

É inteiramente possível que Nicômaco simplesmente não percebeu a conexão entre os dois conceitos. Dada a importância dos números triangulares para a sua aritmética, porém, isto parece um tanto inverossímil. Também não parece provável que ele não poderia fazer as somas necessárias para verificar a conexão nos outros dois casos de números perfeitos por ele conhecidos. Para 496 seria necessário somar os inteiros de 1 até 31, enquanto para 8128 seria necessário somar os primeiros 127 inteiros (positivos). A soma direta, usando um ábaco, seria factível, mas provavelmente usaria uma forma retórica da fórmula para a soma de uma progressão aritmética ou o fato de que dois números triangulares iguais formam um número oblongo ${ }^{6}$. Desta forma, o mais provável é que Nicômaco estava ciente de uma possível conexão entre números perfeitos e números triangulares, mas a julgou inapropriada para um livro introdutório. ${ }^{7}$

Seja isto como for, Nicômaco afirmou que todos os números perfeitos são dados pela fórmula euclidiana, pois alegou que

"There is a method of producing them [números perfeitos], neat and unfailing, which neither passes by any of the perfect numbers nor fails to

\footnotetext{
${ }^{3}$ Nicômaco usa $\alpha$, a primeira letra do alfabeto grego que também representava o número 1 . Outros autores usam o próprio numeral 1.

${ }^{4}$ Uma formulação alternativa e equivalente é que, para $n>0$, o $n$-ésimo número triangular, de lado $n$, é dado por $\frac{n(n+1)}{2}$.

${ }^{5}$ Ver o último parágrafo da presente seção.

${ }^{6}$ Isto é "números hereromécicos", ou seja, números retangulares com lados adjacentes diferendo pela unidade. O uso do termo "oblongo" difere para autores diversos. Nicômaco, por exemplo, reserva "oblongo" para retângulos cujos lados diferem por mais do que uma unidade. Mesmo assim, será expediente usar "números oblongos” por "números hereromécicos" em todos os contextos aqui abordados.

${ }^{7}$ De fato, na última sentença da sua Aritmética, Nicômaco afirma que há muito mais a ser investigado, mas que ele tem apresentado o suficiente para uma obra introdutório.
} 
differentiate any of those that are not such which is carried out in the following way.” (NICHOMACUS OF GERASA, 1938, p. 210.)

Ele continuou em seguida por descrever a referida fórmula. Seria baseado nessa afirmação que ele poderia especular que todos os números perfeitos são triangulares. Foi exatamente isso que aconteceu na primeira abordagem da conexão entre números perfeitos e números triangulares.

\section{Jâmbico}

A Aritmética de Nicômaco foi basicamente reeditado por Jâmblico e traduzida para o latim por Boécio. Os dois autores seguiram de perto o texto do livro de Nicômaco, mas interpolaram alguns acréscimos próprios. Boécio (480-524), no entanto, não parece ter relacionado os números perfeitos e os números triangulares e, assim, voltaremos a nossa atenção para Jâmblico.

Jâmblico (Iamblichus Chalcidensis, c. 242 - c. 325) foi um filósofo e matemático neopitagórico sírio. Segundo Chiaradonna e Lecerf (2019), ele provavelmente nasceu na cidade de Cálcis no norte da Síria, perto de Aleppo. Usamos a edição de Samuel Tennulius de 1668, que dá o texto grego e uma tradução latina em colunas paralelas (ver Iamblichus, 1668). Nesse texto, Jâmblico especula que todos os números perfeitos seriam números hexagonais, o que implica que todos os números perfeitos seriam triangulares, uma vez que, como ele mesmo observou, todos os hexagonais são triangulares.

Na mesma obra, Jâmblico menciona outros sentidos dados ao nome "número perfeito”, mas eles são abordados de forma mais elaborada noutro livro seu ${ }^{8}$, A Teologia da Aritmética, onde lista quatro tipos de números perfeitos. Todos têm em comum a noção de “perfeição" no sentido de ser completo, sem faltar partes. São exemplificados pelos seguintes quatro números (os modos eminentes ${ }^{9}$ ) dentro da Década:

1 É perfeito em que é todo tipo de número em potência e gera todos os números; em especial, é o primeiro número nas várias sequências dos números figurados.

3 É perfeito em que tem início, meio e fim. É suposto que início = meio = fim.

6 É perfeito em que é a soma das suas partes alíquotas.

10 É perfeito em que é a soma do tetraktys e, portanto, engloba tudo que existe. É também o limite de número (num sistema, não necessariamente de notação posicional, de base dez), depois do qual tudo recomeça.

Observo que esses números são os quatro primeiros números triangulares e, portanto, temos um tetraktys de números triangulares perfeitos dentro da Década, o que deveria ter sido

\footnotetext{
8 O referido livro é geralmente atribuído a Jâmblico, mas Waterfield, na introdução à sua tradução do livro (ver [Iamblichus], 1988) afirma que é mais provável que o texto seja notas de um aluno de Jâmblico.

${ }^{9}$ Ver Fossa (1999).
} 
muito significante para Jâmblico, especialmente porque ele considere os números triangulares como "elementos" dos outros números figurados, pois esses podem ser decompostos naqueles.

Devemos nos deter um pouco sobre a perfeição da Tríada. Considerado como números lineares todos os números ímpares (maiores que a unidade) terão esse tipo de perfeição, enquanto os pares não o terão. Mas, alguns dos números hexagonais também exibem a perfeição da Tríada, como é ilustrada na Figura 1 para o terceiro hexágono, 15.

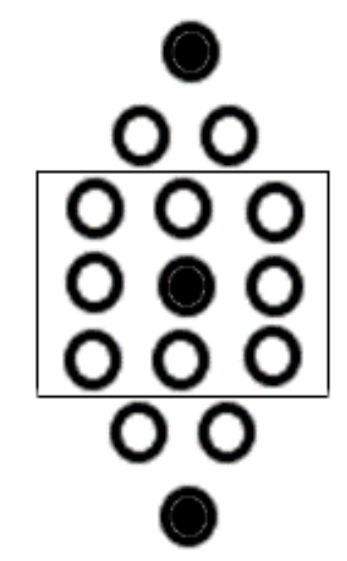

Figura 1.

O mesmo acontecerá sempre que o quadrado intermediário é ímpar, ou seja, acontece para metade dos hexágonos. Desta forma, os triângulos serão alternadamente hexágonos, enquanto os hexágonos serão alternadamente perfeitos:

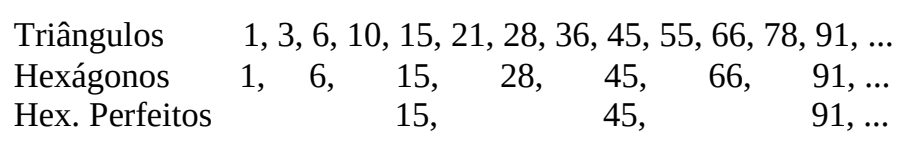

Jâmblico também afirma (ver [Iamblicus], 1988) que o número 6 tem a perfeição de 3, pois pode ser reconfigurado como um retângulo e, desta forma, temos que início = meio $=$ fim $=2$. Algo semelhante ocorre sempre que o lado do hexágono é um múltiplo de 3 ou um múltiplo de 3 menos a unidade (o hexágono de lado $n$ é dado por $n(2 n-1)$ ). Assim, dois terços dos hexágonos podem ser reconfigurados como retângulos com a perfeição de 3. Será interessante, portanto, ver os tipos de perfeição que os hexágonos têm. ${ }^{10}$ Para o início da sequência, onde $3 r$ indica a reconfiguração do hexágono em um retângulo, temos:

\footnotetext{
${ }^{10}$ Isso não coaduna muito como o tipo pitagórico de pensamento, mas permanece uma questão interessante, visto que a investigação de números perfeitos não se limitou a contextos pitagóricos.
} 
$1,6,15,28,45,66,91,120,153,190$,

$\begin{array}{lllllllll}1 & 3_{\mathrm{r}} & 3 & 6 & 3 & 3_{\mathrm{r}} & 3 & 3_{\mathrm{r}} & 3\end{array}$

$63_{\mathrm{r}} \quad 3_{\mathrm{r}} \quad 3_{\mathrm{r}}$

Desta forma, ainda temos que mais ou menos um sexto dos hexágonos não exibe qualquer tipo de perfeição. Acontece, na maioria dos casos, quando o lado $n$ é par e também um múltiplo de três mais a unidade, ou seja, quando $n=6 k+4$; em alguns desses casos, porém, o hexágono tem a perfeição do tipo de 6. Para os primeiros quatro números perfeitos, do tipo de 6, 6 é o segundo hexágono, 28 é o quarto, 496 é o décimo sexto e 8128 é o sexagésimo quarto. Assim, o primeiro hexágono que não exibe qualquer tipo de perfeição é o decimo da sequência, ou seja, 190. Em qualquer caso, concluímos que nem todos os hexágonos exibem algum tipo de perfeição.

\section{Jordanus Nemorarius}

Pouco se sabe do matemático e cientista alemão Jordanus Nemorarius (1225-1260). O próprio nome nemorarius significa "de nemore”, ou seja, “da Silva”, embora haja quem alega que o nome é uma tradução de Giordano de Nemi, sendo Nemi uma cidade perto de Roma. Mas, segundo O’Connor e Robertson (2003), Jordanus nasceu na pequena cidade alemã de Borgentreich, a uns 10 quilômetros de Warburg, e isto é consoante com o sobriquet "da Silva”. Também se sabe que ao regressar de uma visita à Terra Santa, faleceu no mar.

Jordanus foi um matemático de grande prestígio da sua época, atuando nas áreas de aritmética, álgebra, geometria, astronomia e física. Seu manuscrito, De elementis arithmeticae artis, como já indicamos, foi baseado em Boécio e se tornou um texto fundamental para os matemáticos da idade média. Foi impresso em 1496 por Jacques Lefèvre d'Etaples (Jacobus Fabrus Stapulensis), professor de Charles de Bouvelles (ver a próxima seção), e reeditado em 1514 por Henri Estienne (Henricus Stephanus), sob o título Arithmetica decem libris demonstrata.

No oitavo livro da sua Aritmética, Jordanus demonstrou que “Omne perfectu est trinum”"11 de forma retórica, mas essencialmente equivalente à demonstração algébrica. Para tanto, ele supôs que todos os números perfeitos são pares e que têm a forma euclidiana. A suposição é feita na sua demonstração a citar a proposição 60 do Livro VII do seu próprio tratado, interpretando-a como se afirmasse que todo número perfeito tem a forma euclidiana. Na verdade, porém, a referida proposição, tanto na sua formulação, quanto na sua demonstração, afirma a recíproca do que ele supõe.

Referente aos números triangulares, caracteriza-os pela proposição “Cuiuslibet altera parte longioris: medietas est triangularis”, ou seja, qualquer número triangular é metade de um número oblongo (altera parte longioris). Visto que o triângulo tem lados iguais, será necessário, para completar o oblongo a partir do triângulo, acrescentar uma “pedra” ao primeiro lado do triângulo, duas “pedras” à segunda fileira e assim por diante

${ }^{11}$ Todas as citações de Jordanus são de Livro VIII de Jordanus Nemorarius (1514). 
até a última fileira do triângulo que contém uma única "pedra” e, portanto, falta tantas "pedras" quantas são contidas num lado do triângulo original. O processo é ilustrado para o oblongo 4 por 5 na Figura 2. Jordanus ainda observe que o lado do triângulo obtido é igual ao lado menor do oblongo. Em termos algébricos, temos a fórmula para o $n$-ésimo triângulo, $\frac{n(n+1)}{2}$.

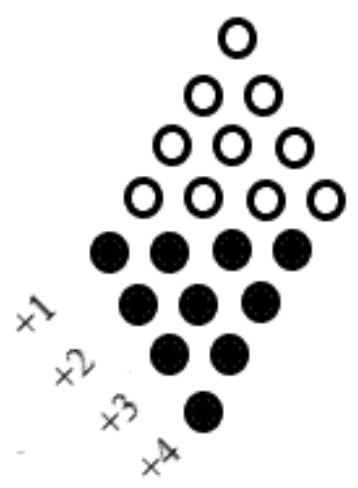

Figura 2.

Assim, basta observar que a relação subduplus (tendo razão 2 para 1) se obtém entre qualquer potência de dois $\left(2^{k}\right)$ e o seu antecessor $\left(2^{k-1}\right)$ para enquadrar os números perfeitos na caracterização dos números triangulares.

\section{Charles de Bouvelles}

Charles de Bouvelles ${ }^{12}$ (1471-1553) pertenceu a uma família aristocrata de Soyécourt ${ }^{13}$, uma pequena comunidade francesa localizada a 24 quilômetros a leste de Amiens e uns 120 quilômetros ao norte de Paris. Estava estudando em Paris, mas desistiu do curso quando a cidade foi assolada pela praga de 1495. Viajou para Suíça, Alemanha, Itália e Espanha, bem como várias partes da França; em seguida foi ordenado padre e eventualmente se estabeleceu em Noyon, uma cidade a uns 65 quilômetros de Amiens. O bispo de Noyon incentivou as pesquisas de Bouvelles, que centraram na matemática, na filosofia e na teologia. Bouvelles se interessou no problema, ainda em aberto na época, da quadratura do círculo e escreveu um pequeno livro sobre os números perfeitos.

A primeira proposição do seu Liber de perfectis numeris alega que "Omnis perfectus numerus est par"14 (BOUILLUS, 1510, p. 171). Isto resulta da sua aceitação, sem

\footnotetext{
${ }^{12}$ As informações biográficas de Bouvelles são retiradas de O’Connor e Robertson (2002).

${ }^{13}$ Assim foi chamado, em latim, Carolus Bouillus (ou Bovillus) Samarobrinus.

14 Na transcrição de textos latinos, não usarei a $s$ alongada, nem reproduzirei as ligaduras e outras marcas diacríticas, mas manterei $v$ para $u$ e $j$ para $i$.
} 
demonstração, que todo número perfeito tem a forma euclidiana, pois todo número dessa forma é claramente par. Provavelmente acatou que todo número perfeito tem a forma euclidiana da autoridade de Jordanus, pois, na sua discussão de números perfeitos cita esse autor.

É só na proposição 21, porém, que Bouvelles faz a conexão entre números perfeitos e números triangulares; em suas próprias palavras, temos:

21 "Omnis igitur perfectus numeris est trinus: eiusque latus est numerus impar primus in quem ductitatur aggregatorum maximus.

Omnis enim perfectus numerus nascitur ductu pariter paris in numerum imparum primum sui duplo vnitate minorem: vt binário in ternarium oritur senarius. Est autem ternarius vnitate: minor quinario binarij duplo. Similiter quaternario in septem octauus et vigemos surgit. Septenario vero minor est vnitate: octonário duplo quaternarij. Est igitur omnis perfectus numerus trigonus ac trinus.” (BOUILLUS, 1510, p. 174.)

A própria proposição 21 faz duas asserções, pois não somente afirma que todo número perfeito é triangular, mas também assevera que a base (latus, "lado") do triangulo é o número primo ímpar dado pela fórmula de Euclides.

A demonstração começa com a repetição da proposição geral que todo (omnis) número perfeito é o produto de uma potência de 2 (pariter paris ${ }^{15}$ ) e um primo que é seu duplo menos a unidade, conforme reza a fórmula de Euclides. O resto da demonstração, porém, é por exemplificação. Para entendê-la, será útil ver primeiro como Bouvelles gera os números triangulares.

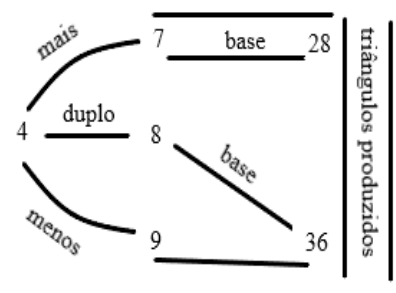

(i)

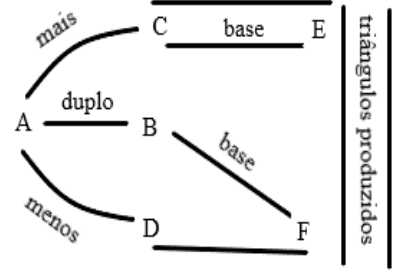

(ii)

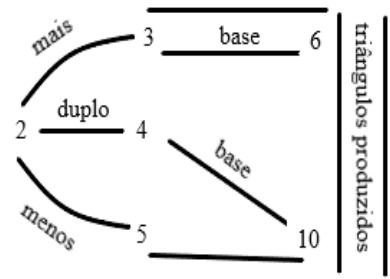

(iii)

Figura 3.

A Figura 3(i) é dada pelo próprio Bouvelles. A Figura 3(ii) simplesmente nomeia as várias posições dentro do esquema. Se começamos com 4 na posição $\mathrm{A}$, colocamos o seu duplo, 8, na posição $\mathrm{B}$. O número na posição $\mathrm{B}$ deve ser uma unidade a mais do número na

\footnotetext{
${ }^{15}$ A expressão correspondente do grego é traduzida por Bicudo por “par, um número par de vezes” e Heath, “even times even”.
} 
posição $\mathrm{C}$ e uma unidade a menos do número na posição $\mathrm{D}$. Assim, colocamos 7 na posição C e 9 na posição D. O número na posição $\mathrm{E}$ é o produto dos nas posições $\mathrm{A}$ e C; esse produto será o número triangular cuja base é dada pelo número na posição C. De fato, $4 \times 7$ $=28$, o triângulo com base 7 , visto que $28=1+2+3+4+5+6+7$. De modo semelhante, o número na posição $\mathrm{F}$ é o produto dos nas posições $\mathrm{A}$ e $\mathrm{D}$; esse produto será o número triangular cuja base é dada pelo número na posição B. De fato, $4 \times 9=36$, o triângulo com base 8 , visto que $36=1+2+3+4+5+6+7+8$.

$\mathrm{O}$ procedimento descrito no parágrafo anterior com referência à Figura 3(i) corresponde ao segundo exemplo dado por Bouvelles na sua demonstração da proposição 21. Mostra que o número perfeito 28 é um número triangular com base 7. O primeiro exemplo de Bouvelles faz o mesmo raciocínio para o número perfeito 6. Desenvolvi a estrutura para esse caso em Figura 3(iii). Ao colocar 2 na posição A, seu dobro, 4 vai para a posição B. Assim, 4-1 = 3 e 4+1 = 5 são colocados, respectivamente, nas posições C e D. Na posição $E$ colocamos $2 \times 3=6$ e, portanto, o número perfeito 6 é um triângulo com base 3. Completamos a Figura por colocar $2 \times 5=10$ na posição $F$, mostrando que 10 é triangular com base 4 . Observamos que tanto 10 , quanto 36 , são números triangulares, mas não são perfeitos, o que demonstra definitivamente (caso fosse necessário!) que nem todo número triangular é um número perfeito.

\section{A Validade do Argumento de Bouvelles}

Com base nos dois exemplos, Bouvelles concluiu que todo número perfeito é triangular. Parece, então, que o seu argumento é inválido, pois seria uma indução incompleta como a de concluir que $f(n)=n^{2}+n+41$ é sempre primo porque $f(1)=43$ e $f(2)=47$. Pior ainda, Bouvelles, na sua demonstração, nem aborda explicitamente a segunda parte da proposição referente à base do triângulo.

O procedimento de Bouvelles, contudo, é válido, embora contenha uma premissa não comprovada, pois não depende do cálculo de vários casos independentes, como acontece na indução incompleta, mas consiste em fornecer um exemplo (ou mais) que serve como um template para todos os casos. Chamo esse procedimento de demonstração por exemplificação. Era muito usado na história da matemática e é, de fato, um procedimento válido, embora, pelos padrões hodiernos não é considerado satisfatório porque a sua validade nem sempre é evidente, especialmente quando é usado num contexto retórico. Assim, será instrutivo usar métodos simbólicos para mostrar a generalidade do argumento de Bouvelles.

Começamos com o procedimento de gerar números triangulares. Para tanto, observamos que qualquer inteiro positivo pode ser representado por $\frac{n}{2}$ para algum $n$. Assim, colocamos $\frac{n}{2}$ na posição A da estrutura de Bouvelles (ver a Figura 4) ${ }^{16}$ Desta forma, $n$, seu duplo, ocupará a posição B, enquanto $n-1$ e $n+1$ ocuparão, respectivamente, as posições $C$ e

\footnotetext{
${ }^{16}$ De fato, Bouvelles só considera (proposição 19) o caso especial em que a posição A é ocupado por uma potência de 2. Mostraremos, no entanto, que o procedimento é mais geral.
} 
D. Logo, $\frac{n}{2} \times(n-1)$ será colocado na posição $E$, Mas, isso é precisamente $\frac{n(n-1)}{2}$, a fórmula, que já vimos, para o n-1-ésimo número triangular, cuja base é, portanto, $n-1$. Assim, o número na posição $\mathrm{E}$ é, na verdade, um número triangular e a sua base é dada pelo número na posição C. Semelhantemente, $\frac{n}{2} \times(n+1)$ será colocado na posição F; mas isso é precisamente $\frac{n(n+1)}{2}$, a fórmula para o $n$-ésimo número triangular (ver a nota 4 ), cuja base é, portanto, $n$. Assim, o número na posição $\mathrm{F}$ é, na verdade, um número triangular e a sua base é dada pelo número na posição $\mathrm{B}$.

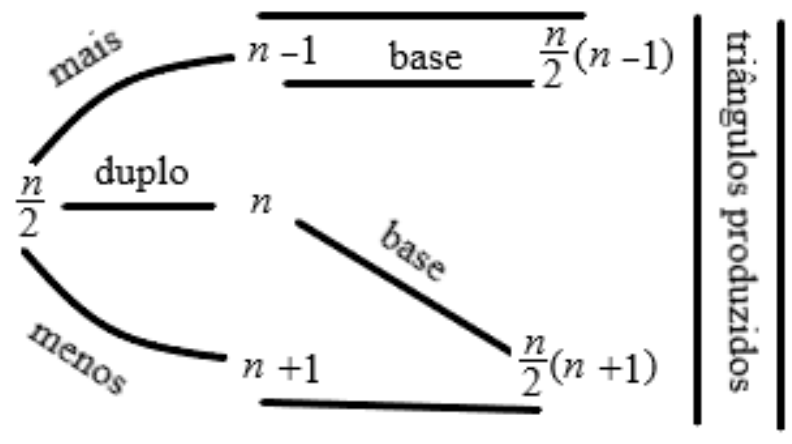

Figura 4.

Poderemos dizer ainda um pouco mais, pois, ao deixar $\frac{n}{2}$ percorrer os números inteiros positivos na sua ordem natural, serão gerados todos os números triangulares, em ordem. Isto fica evidente ao considerar $\frac{n}{2}+1$. Seja $X_{1}$ e $X_{2}$ as posições de duas estruturas de Bouvelles, pois, ao colocar $\frac{n}{2}$ em $A_{1}$ e $\frac{n}{2}+1 A_{2}$, obtemos $n-1, n, n+1$ e $n+2$ em, respectivamente, as posições $C_{1}, B_{1}, C_{2}$ e $B_{2}$.

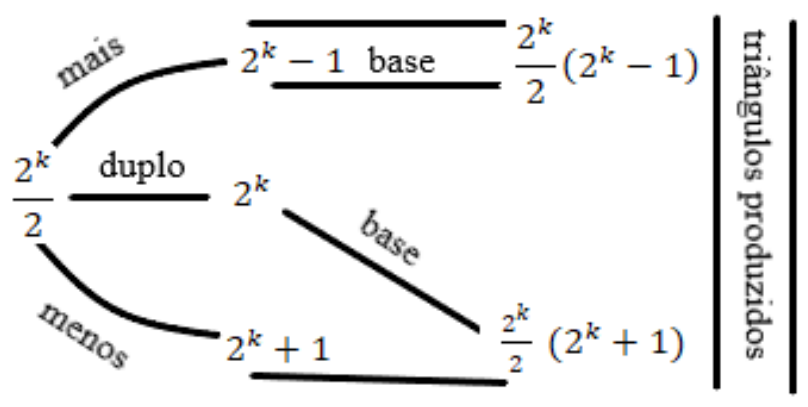

Figura 5.

RBHM, Vol. 20, n 40, pp. 32-45, 2020 
Agora só falta mostrar que o procedimento de Bouvelles demonstra que o número perfeito arbitrário $2^{k-1}\left(2^{k}-1\right)$ é um número triangular. Para tanto, observamos que $2^{k}$ é um número par e, portanto, $\frac{2^{k}}{2}$ é inteiro. Assim, ao colocar $\frac{2^{k}}{2}$ na posição A, seu dobro, $2^{k}$, ficará na posição B (ver a Figura 5). A posição C conterá $2^{k}-1$ e $\frac{2^{k}}{2}\left(2^{k}-1\right)$ ocupará a posição E. Logo, do que vimos sobre a estrutura de Bouvelles, $\frac{2^{k}}{2}\left(2^{k}-1\right)$ é um número triangular com base $2^{k}-1$. Mas, $\frac{2^{k}}{2}\left(2^{k}-1\right)=2^{k-1}\left(2^{k}-1\right)$. Portanto, $2^{k-1}\left(2^{k}-1\right)$ é um número triangular com base $2^{k}-1$.

As considerações do parágrafo anterior mostram que o argumento de Bouvelles, embora contenha uma premissa não comprovada, é válido. (Os números nas posições D e F da Figura 5 são irrelevantes para esse propósito.) De fato, seu procedimento é equivalente ao expediente algébrico simples de substituir $\frac{2^{k}}{2}$ por $2^{k-1}$. No contexto do seu argumento, porém, isto não é suficiente porque ele não usa uma representação algébrica abstrata para representar os números triangulares. Assim, a sua estrutura provê um template para a resolução retórica do problema.

\section{Francesco Maurolico}

O padre beneditino Francesco Maurolico (1494-1575) nasceu em Messina (Sicília) a uma família de procedência grega. Ele se dedicava principalmente à matemática e à astronomia, mas também foi ativa no governo da ilha, servindo como o diretor da casa da moeda da Sicília e como chefe das fortificações de Messina. Era também professor de matemática na primeira faculdade jesuíta a ser fundada (atualmente a Universidade de Messina) por Ignácio de Loyola (1491-1556). Seu trabalho matemático foi de alta qualidade para a época, embora foi contrário à teoria copernicana. ${ }^{17}$

Seus Arithmeticorum libri duo (Dois livros aritméticos) foram escritos em 1557, mas só publicados em 1575 nos Opuscula mathematica, que também contêm várias outras obras suas sobre a matemática. Em Maurolycus (1557, p. 10), ele demonstra que "Omnis numerus perfectus est triangulis" por demonstrar primeiro que todo número perfeito é hexagonal; visto que os hexágonos são todos triângulos, o resultado segue como corolário. Para tanto, supõe implicitamente que todos os números perfeitos são dados pela fórmula euclidiana.

Sua demonstração é completamente retórica, mas corresponde exatamente a formulação algébrica. Assim, mostra que os números hexagonais são dados pela radix ("raiz" ou "base" - diríamos "índice”) vezes o número ímpar correspondente. Isto é, o $n$ ésimo número hexagonal é o produto do próprio $n$ com o $n$-ésino número ímpar. Mas, se deixarmos a radix ser um número da progressão duplo, o número ímpar correspondente será o próximo número da referida progressão, menos a unidade, e, quando este é primo, teremos um número perfeito pela fórmula euclidiana.

${ }^{17}$ Para mais detalhes sobre a vida de Maurolico, ver, por exemplo, O’Connor e Robertson (2010). 


\section{Desenvolvimentos Posteriores}

Vários outros pensadores, como, por exemplo, Bungus (1614) ${ }^{18}$ ou Puteanus (1637), alegaram que todos os números perfeitos são triangulares, mas em geral apenas mencionaram isto ou não apresentaram novidades. Por volta dessa época, porém, houve certo interesse tanto em demonstrar explicitamente a recíproca do teorema de Euclides, quanto em descobrir números perfeitos ímpares. Entre os que compartilharam esse interesse, podemos mencionar René Descartes (1596-1650), Pierre Fermat (1607-1665) e Bernard Frenicle de Bessy (?-1675) ${ }^{19}$. A primeira demonstração satisfatória da recíproca do teorema de Euclides, ou seja, $p$ é perfeito par $\Rightarrow p=2^{k-1}\left(2^{k}-1\right)$, onde $k$ é um inteiro positivo e $2^{k}-1$ é primo, foi dada por Leonhard Euler (1707-1783). Como já mencionamos na seção inicial do presente trabalho, a demonstração se encontra em Euler (1849), um artigo póstumo sobre números amigáveis. O resultado foi certamente conhecido muito antes, porém, pois, segundo Eneström $(1913)^{20}$, o referido artigo foi apresentado à Academia de Berlim em 1747.

Com a demonstração de Euler da recíproca do teorema de Euclides, as demonstrações anteriores de Jordanus, Bouvelles e Maurolico são redimensionadas, pois a premissa implícita foi trazida à tona e validada. Mesmo assim, é necessário modificar a conclusão para: todo número perfeito par é triangular.

Visto que a existência de números perfeitos ímpares é ainda uma questão em aberto, há três possibilidades sobre o caso geral. A demonstração que não haja números perfeitos ímpares implicaria que todo número perfeito é triangular. A descoberta de números perfeitos ímpares, porém, não resolveria necessariamente a questão porque todos eles poderiam ser triangulares, ou pelo menos um deles poderia não o ser.

\section{Conclusão}

A história da procura por números perfeitos é repleta de erros matemáticos. Muito deles são oriundos da dificuldade de determinar, na ausência de mecanismos automatizados de calcular, a primalidade de números muito grandes. Mas, outros são erros de raciocínio como o de não discriminar entre condições necessárias e condições suficientes. Há, ainda mais, erros historiográficos, como o do matemático alemão Georg Wolfgang Kraft (17011754), apontado pelo investigador italiano Mariano Fontana (1746-1808), pois segundo Kraft a proposição de que todo número perfeito é triangular era devida ao seu colega alemão, Tobias Maier ${ }^{21}$ (1723-1762). Nas próprias palavras do cientista italiano, temos:

“Da questa formola conchiudesi tutti i numeri perfetti appartenersi alla serie de'numeri triangolari. Conseguenza, che no so se attribuire si debba o a Majer inventore, o a Krafft espositore del metodo, poichè

\footnotetext{
${ }^{18}$ Originalmente 1591.

${ }^{19} \mathrm{O}$ ano de nascimento de Frenicle é dado, por vários historiadores, como 1602, 1605 ou 1612.

${ }^{20}$ No site dado nas referências, há um link para a tradução para o inglês feita por Greta Perl em 2004.

${ }^{21}$ Pai do físico Johann Tobias Maier (1752-1830). Em alemão o sobrenome é escrito Mayer.
} 
quest'ultimo nol dice. So bene che più d'un secolo e mezzo prima lo stesso con fino raziocinio aveva conchiuso Maurolico; siccome vedesi nella proposizione $25^{a}$. del primo libro. Ma v'è anche di più. Già nella prop. $24^{a}$. aveva dimostrato, che ogni numero perfetto si contiene nella serie degli esagoni, cioè aveva chiusi i numeri perfetti in un complesso di termini quasi della metà più pochi, che non fecero poi Majer, e Krafft." (FONTANA, 1808, p. 285-286.)

Assim, Fontana, ao corrigir um erro, faz outro, pois alega que a referida proposição se deve ao Maurolico e ainda enaltece o trabalho de Maurolico pelo fato que este conseguiu enquadrar os números perfeitos nos hexágonos, uma classe mais restrita do que a dos triângulos. Como vimos, Jordanus e Bouvelles deram argumentos para a mencionada proposição e Jâmblico (bem como, possivelmente, Nicômaco) havia especulado que todo número perfeito é hexagonal. Mesmo assim, Maurolico parece ser o primeiro a dar um argumento para a proposição de que todo número perfeito é um hexágono, embora seu argumento contém a mesma falha dos de Jordanus e Bouvelles.

A proposição sob discussão deveria ter sido considerada como tendo certa importância para os antigos, pois, para eles, os números figurados eram carregados com significado esotérico. Também eram usados, na ausência de um simbolismo algébrico mais robusto, para formular proposições matemáticos. Com o eventual abandono do pitagorismo e o desenvolvimento do simbolismo algébrico, contudo, o fato de que todo número perfeito par é triangular (hexagonal) perdeu sua carga esotérica e tornou-se uma curiosidade interessante.

\section{Referências}

BOUILLUS (Samarobrinus), Carolus. 1510. Liber de perfectis numeris. (Escrito em 1509.) In: BOUILLUS (Samarobrinus), Carolus. 1510. Sem título. Paris. [p. 171-180.] Disponível em: <books.google. com.br >. Acesso em 30/09/2020.

BUNGUS, Petrus. 1614. Numerorum mysteria. Bérgomo. Disponível em: <books.google. com.br>. Acesso em 16/10/2020.

CHIARADONNA, Ricardo, e LECERF, Adrien. 2019. Iamblichus. In: Stanford Encyclopedia of Philosophy. Disponível em: <plato.stanford.edu/entries/Iamblichus>. (2019). Acesso em 08 de 10 de 2020.

ENESTRÖM, Gustav. 1913. Die Schriften Eulers chronologisch nach den Jahren geordnet, in denen sie verfasst worden sind. Disponível em: <http://eulerarchive.maa.org/>. Acesso em $18 / 10 / 2020$.

EUCLID. 1956. The Thirteen Books of the Elements. T. L. Heath (Ed.). New York: Dover. EUCLIDES. Os Elementos. 2009. Trad. Irineu Bicudo. São Paulo: Editora UNESPE.

EULER, Leonhard. 2015. Sobre números amigáveis. Trad. Fabricio Possebon e John A. Fossa. In: EULER, Leonhard. Sobre Números Amigáveis. Ed. John A. Fossa. Natal: Editora da UFRN. 
EULER, Leonhard. 1849. De numeris amicabilibus. In: Commentationes Arithmeticae Collectae (Vol. 2). Ed. P. H. Fuss e Nicolaus Fuss. São Petersburgo: Academia Imperial das Ciências de São Petersburgo.

FONTANA, Mariano. 1808. Osservazioni storiche sopra l'aritmetica di Francesco Maurolico. Memorie dell'Istituto Nazionale Italiano. Classe di Física e Matematica. Tomo secondo, parte prima. Bologna.

FOSSA, John A. 1999. Uma Caracterização da Matemática Platônica. In: Circe Mary Silva da Silva (Ed.). Anais do III Seminário Nacional de História da Matemática. Vitória: UFES. IAMBLICHUS. 1668. In Nicomachi Geraseni arithmeticam introductionem. Samuel Tennulius (Ed.) Arnheim. Disponível em: <books.google. com.br>. Acesso em 08 de 10 de 2020.

[IAMBLICHUS]. 1988. The Theology of Arithmetic. Trad. Robin Waterfield. Grand Rapids.

MAUROLYCUS, Franciscus. 1575. Arithmeticorum libri duo. Veneza. Disponível em: <books.google. com.br>. Acesso em 16 de 10 de 2020.

NICOMACHUS OF GERASA. 1938. Trad. Martin Luther D’Ooge. Introduction to Arithmetic. Ann Arbor: University of Michigan Press.

O’CONNOR, J. J, e ROBERTSON, E. F. 2010. Francesco Maurolico. Disponível em: <https://mathshistory.st-andrews.ac.uk/Biographies/Maurolico/>. Acesso em 16/10/2020. . 2003. Jordanus Nemorarius. Disponível em: <https://mathshistory.st-andrews.ac.u k/Biographies/Jordanus/>. Acesso em 03/10/2020.

. 2002. Charles de Bouvelles. Disponível em: <https://mathshistory.st-andrews.ac.u k/Biographies/Bouvelles/>. Acesso em 03/10/2020.

PUTEANUS, Erycius. 1637. De bissexto liber. Lovaina. Disponível em: <books.google. com.br>. Acesso em 16/10/2020.

\section{John A. Fossa}

Universidade Estadual da Paraíba - UEPB - Brasil

E-mail: jfossa03@gmail.com 